\title{
Memórias da Universidade: Lapsos e Lembranças
}

\author{
University's Memories: Lapses and Remembrance
}

RESUMO

O texto se detém sobre os projetos contemplados pelo Edital Memória lançado pela Pró-Reitoria de Cultura e Extensão Universitária, de modo a realizar um balanço crítico das propostas, em função de seus pontos comuns e de alguns silêncios, esperando iluminar perspectivas futuras. Fruto de uma intervenção realizada no seminário Balanço e Perspectivas (USP, novembro de 2014), ele mantém deliberadamente o tom de exposição oral, tal como foi concebido.

Palavras-chave: Edital Memória USP. Patrimônio Universitário. Cultura, Memória e Identidade. Acervos e Documentos.

\section{ABSTRACT}

The text observes the contemplated projects of the Edital Memória, presented by the Provost for Culture and Extension of the University of São Paulo, in order to produce a critical analysis of the proposals, according to the common points and some silences, expecting to illuminate future perspectives. As a result of an intervention held at the seminary Balanço e Perspectivas (USP, November 2014), it has sustained deliberately the aspects of the oral exposition, just as it was conceived.

Keywords: Notice Memória USP. Academic Heritage. Culture, Memory and Identity. Collections and Documents.

Este texto possui história e motivações precisas que merecem ser indicadas para que faça sentido, tanto a forma oral, que deliberadamente possui, quanto o teor dos argumentos apresentados. Trata-se de uma reflexão motivada pelo seminário $\mathrm{Ba}$ lanço e Perspectivas, organizado pela Pró-Reitoria de Cultura e Extensão em novembro de 2014, que previa uma avaliação dos projetos contemplados pelos editais lançados

FERNANDA ARÊA

Peixoto

Universidade de São Paulo. Faculdade de Filosofia, Letras e Ciências Humanas, São Paulo, Brasil 
nos anos anteriores (2012 e 2013), voltados para a preservação de acervos, memórias e monumentos da Universidade de São Paulo. A minha intervenção em uma das sessões do seminário tinha como objetivo definido de antemão: realizar um balanço dos trabalhos contemplados por um dos editais, o Memórias USP, trabalhos que auxiliei a selecionar como membro de uma das comissões julgadoras. Dessa forma, e antes de qualquer outra coisa, agradeço ao convite feito para participar de todo o processo, da avaliação ao balanço final, processo que trouxe novos aportes às minhas próprias pesquisas e reflexões individuais, parte delas relacionadas à Universidade.

Vale a pena insistir sobre os inegáveis méritos da iniciativa, voltada ao estabelecimento de políticas dirigidas ao patrimônio universitário, e na grande recepção que ela obteve junto à comunidade acadêmica, mostram as 213 propostas apresentadas, originárias das mais diversas unidades da USP. Lembremos também que dos três editais, o Memória foi o menor deles, em termos de recursos e de número de projetos aprovados: estamos falando aqui de 23 concessões em um universo de 55 propostas enviadas para exame* ${ }^{*}$ E é sobre este conjunto de projetos que pretendo me deter brevemente; trata-se, insisto, de uma apreciação empreendida a partir das propostas e não de seus resultados.

Um olhar panorâmico sobre esse material deixa ver alguns de seus traços mais salientes. De um ponto de vista geral, estamos falando de projetos provenientes das áreas de ciências humanas (17 dos 23), o que nos leva a pensar, de saída, que assuntos e políticas de memória mobilizam fundamentalmente o domínio das artes e das humanidades. Se isso é verdade, os contemplados se distribuem por unidades e setores variados**: das 23 propostas, cinco são originárias da Faculdade de Filosofia, Letras e Ciências Humanas (FFLCH); duas da Faculdade de Educação (FE); duas da Reitoria; e as demais se distribuindo por diferentes unidades: Instituto de Estudos Brasileiros (IEB); Faculdade de Arquitetura e Urbanismo; Instituto de Arquitura e Urbanismo; Museu de Arte Contemporânea (MAC); Orquestra Sinfônica da USP; Museu Paulista e Faculdade de Psicologia. Diante desse quadro, considero que um dos desafios que se coloca para iniciativas futuras é conseguir sensibilizar as demais áreas do conhecimento, alargando e diversificando o escopo das demandas.

Apoiada nesse corpus preciso, e aproveitando minha própria experiência como avaliadora dos projetos, a intenção aqui é destacar certas trilhas recorrentes e alguns silêncios observados nas proposições, que serão trazidos à baila não com vistas a cobrar deslizes ou omissões, mas para lançar uma reflexão - de clara dimensão auto-reflexiva, como mencionei antes - sobre o que tendemos a incluir e a desconsiderar quando falamos em memória da Universidade. Na mesma direção, é importante salientar que as eventuais referências a projetos específicos ao longo do texto não visam nomear àqueles considerados "melhores" ou "piores", funcionando apenas

\footnotetext{
*Ao edital de Preservação de Acervos e Patrimônio Cultural foram submetidas 110 propostas, das quais 67 foram contempladas; 58, por sua vez, se apresentaram ao edital de Intercâmbio de Atividades de Cultura e Extensão, tendo sido 39 aprovadas.
}

**Garantir a diversidade institucional foi, aliás, uma das preocupações da comissão avaliadora. 
como um modo de aproximar o leitor dos projetos em exame - todos eles, aliás, de interesse inquestionável. Estas notas fornecem assim um retrato sintético, composto em função de traços gerais, esperando contribuir para animar o debate e, sobretudo, para orientar perspectivas futuras, o que me parece ser o aspecto mais importante.

\section{BALANÇO}

Aproximando o foco do material disponível, é possível avançar na apreensão de sua matéria. Vemos, assim, como os projetos contemplados cobrem o arco de objetivos definidos pelo edital em questão: memória das instituições e institutos que compõem a universidade; memória dos seus espaços; memória da produção científica, artística e cultural; e memória sociocultural dos diversos grupos sociais que a universidade abriga. Isso se deve, claro, à atuação da comissão avaliadora, atenta ao ponto, mas, sobretudo, ao conteúdo substantivo das propostas, que permitiu atender às prioridades definidas pelo programa.

Gostaria de sublinhar o que julgo ser um ponto forte dos projetos: o seu interesse pelas mais variadas expressões da produção científica: produção docente e discente; teses, revistas, anuários, imagens e documentos de ocasião (relatórios, memoriais, trabalhos de cursos, projetos de pesquisa, planos de aulas, cadernos de campo etc.). Quer dizer, os projetos mostram uma compreensão ampliada do que é produção universitária, relacionando-a ao dia-a-dia da universidade, aos professores, mas também aos alunos e funcionários, e ainda a outros grupos sociais aí atuantes ${ }^{* * *}$. As propostas incluem a pesquisa, em seus diferentes níveis e resultados - teses, livros e bibliotecas -, mas também a docência (cursos regulares e extracurriculares) e as produções que têm lugar em sala de aula (aulas magnas e trabalhos escolares), nos conduzindo a uma compreensão alargada de patrimônio universitário, pela valorização de práticas, produções, acervos e experiências ordinárias, algumas difíceis de serem captadas, como o burburinho das agremiações estudantis, o cotidiano dos funcionários e certas experiências individuais, que os arquivos pessoais e depoimentos auxiliam a conhecer.

Mas se tal perspectiva ampliada se faz notar na consideração das produções e produtos da universidade, quando se trata da recuperação de personagens específicos da vida universitária, docentes e discentes, nota-se uma certa redução do foco. A tendência neste caso é tomar aqueles que se tornaram célebres, os que ganharam notoriedade dentro ou fora da Universidade: alunos que se converteram em artistas conhecidos (cartunistas, cineastas, críticos e compositores) ou docentes/ pesquisadores que deixaram grandes obras, reconhecidas dentro e fora da universidade, dentro e fora do país.

Diante disso, pergunto se não seria possível, aí também, expandir a perspectiva,

\footnotetext{
***Por exemplo, o grupo de capoeira Guerreiros da Senzala, na origem do Núcleo de Cultura e Extensão em Artes Afro-brasileiras da USP, objeto de um dos projetos apresentados, ou os músicos engajados na Orquestra Sinfônica da universidade, cuja história é o foco de interesse de um outro projeto.
} 
incluindo de forma mais sistemática personagens localizados nos "bastidores". A questão, vale observar, nada tem a ver com a defesa de figuras de menor notoriedade, na linha da "história dos vencidos", mas busca indagar se esses outros nomes, que acabaram longe do proscênio, não poderiam nos conduzir à compreensão de dimensões fundamentais da vida universitária, deslocando os caminhos comumente percorridos e, mais uma vez, ampliando o entendimento do patrimônio universitário.

O exame dos materiais leva a pensar também em outros silêncios dos projetos, sobre as quais pode ser interessante refletir. Chama a atenção, por exemplo, os documentos burocráticos, ausentes das propostas e, salvo engano, dos nossos trabalhos e pesquisas de modo geral. São pareceres, despachos, solicitações, formulários, relatórios, planos departamentais, entre outros, papéis colados às rotinas comezinhas, que circulam entre setores e salas até virarem "arquivo morto", literalmente enterrados em caixas de papel pardo depositadas no alto dos armários. Documentos sem glamour, é verdade, mas que proliferam na universidade hoje e que ocupam grande parte de nosso tempo. Não seriam eles parte da produção universitária, matéria fundamental para a compreensão da Universidade e para o traçado de sua memória?

Levar a sério esses objetos desencantados, olhando-os não como antíteses da produção científica, mas como "artefatos do conhecimento", é o que propõem Annelise Riles e seus colaboradores [5], que ousam uma "etnografia dos documentos", analisando-os do ponto de vista de sua forma e conteúdo. Registros de entrada de prisioneiros em Papua Nova Guiné; cartas de recomendação de uma fundação norte-americana; escritos produzidos por ocasião de uma missão universitária; o documento final de uma grande conferência internacional; prontuários médicos, entre outros, compõem os documentos sobre os quais se debruçam os pesquisadores. Os trabalhos têm, entre outros méritos, o de retomar a análise burocrática, afastando-se da conhecida trilha weberiana, que vê o sistema burocrático como instrumento de poder e dominação, e exercitando uma perspectiva etnográfica diante dos seus produtos, o que permite flagrar seus dispositivos e modus operandi.

Um dos alertas metodológicos que esses estudos lançam diz respeito ao modo de interpretar esse tipo de documento, que obriga a elaboração de novas ferramentas interpretativas. Isto porque, ainda que estejamos diante de materiais escritos, nada mais distante do modelo textual que nos é familiar, sobretudo nas Ciências Humanas. Afinal, longe de se apresentarem como narrativas, os documentos em questão possuem formas específicas - o formulário, por exemplo -, impondo novas direções de leitura (muitas vezes vertical) e chamando a nossa atenção para as dimensões visuais e gráficas que o constituem (células e parêntesis).

Tais documentos deixam ver, ainda, que estamos diante de formas que preveem determinados conteúdos e que se reproduzem de modo veloz: o preenchimento de um formulário gerando outros, o adendo feito a um relatório por meio de um colchete criando um novo, e assim sucessivamente. Além disso, todas essas novas criações encontram-se submetidas a esquemas convencionados que as constrangem, o "novo" assumindo, em seguida, aspecto de déjà vu. A repetição é assim outro elemento fundamental a ser considerado quando da análise desses materiais, cuja forma se alimenta da reposição sistemática de padrões. 
Ainda na linha de localizar silêncios que nos auxiliem a abrir novas veredas na compreensão do patrimônio universitário, gostaria de salientar duas outras ausências dos projetos. Uma delas, as paisagens naturais, que são, em geral, esquecidas. A história dos edifícios ou dos espaços construídos ${ }^{* * *}$ pouco inclui as suas relações, seja com outras paisagens (as naturais, como dito), seja com os entornos urbanos ${ }^{* * * * *}$. Isto nos leva a pensar que as propostas tendem a focalizar fachadas, arquiteturas e interiores das edificações, assim como a vida intramuros.

Em segundo lugar - e neste caso, ao contrário do anterior, há apenas uma exceção, um projeto dedicado aos impactos da ditadura militar na universidade - é perceptível a falta de referências aos conflitos e tensões que marcam a vida universitária em suas mais diversas dimensões, e que o edital menciona expressamente, o que é de seus méritos. Tal silêncio nos leva a pensar que a recuperação da memória liga-se à celebração dos resultados positivos, das parcerias e projetos exitosos, o que é compreensível. Afinal, como falar dos problemas e impasses - alguns deles na origem do redesenho institucional de certos departamentos e institutos -, dos planos abortados, das teses não defendidas e dos projetos não realizados? Mas se tal memória "traumática" não se faz presente nos textos, ela está completamente viva, circulando nos corredores, nas conversas de bastidores, bem sabemos, ainda que pareça resistir a ser narrada de outro modo, recusando-se a se fixar nos textos escritos.

Ciente das dificuldades (políticas e pessoais) envolvidas na tarefa, me parece importante levantar o ponto, nem que seja para que ele possa funcionar como um elemento dissonante, capaz de nos auxiliar a pensar em como lidamos com a memória em geral e com a memória universitária, em particular. A memória da Universidade seria fundamentalmente homenagem e celebração? Ou, em outros termos, como escapar dos riscos de exaltação e dos panegíricos que rondam a construção de memórias, sejam elas institucionais ou biografias?**

\section{PERSPECTIVAS}

Deixando, neste momento, de lado os silêncios e pensando em ênfases que, me parece, deveriam orientar os projetos sobre memória e patrimônio universitário. Além das ponderações feitas na primeira parte do texto, gostaria de sublinhar como o registro de elementos do passado é inseparável de uma reflexão sobre ele; reflexão, aliás, que

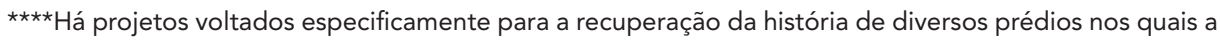
universidade funcionou, ou nos quais, eventualmente, ainda funciona.

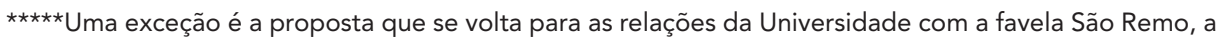
partir da retomada dos projetos educacionais e culturais elaboradas pela Universidade para a população carente dessa comunidade localizada nas vizinhanças do campus universitário.
}

$\star \star \star \star \star \star *$ Vale observar que mesmo o projeto dedicado à ditadura militar e aos seus efeitos apresenta-se expressamente como uma "homenagem às vítimas da ditadura". Aliás, os termos "celebração" e "homenagem" acompanham boa parte das propostas. 
orienta a sua própria recuperação e inscrição no presente. $\mathrm{O}$ edital menciona este aspecto, algumas propostas se referem a ele, mas parece fundamental trazê-lo ao primeiro plano. Em outros termos: a dimensão reflexiva e/ou problemática deve tomar a dianteira nas propostas relativas ao patrimônio universitário, e nem sempre é isso que ocorre; a homenagem teima em funcionar como uma espécie de anteparo ou de escudo protetor que tende a afastar a análise crítica.

O que está efetivamente ocupando a cena primeira, conduzindo planos e projetos sobre a memória universitária, de acordo com os projetos apresentados? Fundamentalmente, a ideia de "resgate", termo presente em todas as propostas. $\mathrm{O}$ intuito generalizado é o de resgatar uma experiência, uma obra ou história. E à tarefa de resgate associa-se frequentemente um sentido de urgência: urgência diante do desaparecimento de fontes e materiais, diante da perda de registros físicos e de pessoas.

Como antropóloga, sou bastante sensível a esse tipo de retórica, já que ela acompanha o nascimento mesmo da antropologia como disciplina, desde o século XIX: é preciso estudar os primitivos em "vias de extinção". Nós antropólogos nos constituímos, assim, sob o signo da perda e da destruição, e este parece ser também o caso dos profissionais envolvidos com o patrimônio histórico, cultural e arquitetônico, as voltas com a "recuperação", com a "revitalização" e com o "salvamento" de bens culturais os mais variados. Mas se os antropólogos, por vários razões, estamos alertas para esse sentimento e discurso - até porque os "primitivos" não desapareceram, a despeito das políticas que visaram à sua eliminação -, quando o assunto é memória e patrimônio, a "retórica da perda", nos termos de José Reginaldo Gonçalves [4], assim como o compromisso com o resgate, teimam em ocupar o centro das preocupações.

Os riscos implicados em conferirmos ao resgate maior estatura que à tarefa reflexiva propriamente dita não são poucos (ainda que o engajamento político com as questões patrimoniais que tal adesão pressupõe seja meritório e louvável). Em primeiro lugar porque a noção mesma de resgate dá a falsa impressão de que tais experiências passadas estão depositadas, ou presas, em dado lugar do passado e que devem ser recuperadas, libertadas do esquecimento ${ }^{* * * * * *}$. Na antropologia, o termo se associa frequentemente às noções de cultura e identidade, que terminam estabilizadas como se fossem dotadas de conteúdos prévios, passíveis de serem identificados de antemão: culturas a serem "preservadas em sua pureza e/ou originalidade"; identidades últimas a serem "assumidas" ou "resgatadas". Se a identidade não "é", apresentando-se como um permanente devir em função das relações (diferenças) entre grupos, a cultura, por sua vez, é pura invenção e mudança, bem o sabemos*******.

Em segundo lugar, a ideia de resgate acaba, também, por deixar de lado o aspecto

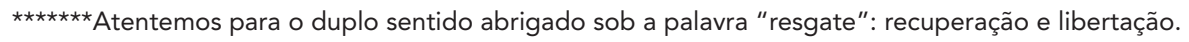

$\star \star \star \star \star \star \star \star \star$ Claro está que os termos cultura, identidade e memória são frequentemente tomados como bandeiras políticas pelos atores e movimentos sociais, e os diversos sentidos que eles adquirem no mundo social devem ser descritos e interpretados, sem que os intérpretes os tomem como categorias analíticas. Para uma reflexão sobre cultura, identidade e etnicidade, cf.[1]; sobre a noção de cultura e suas derivas, ver [2].
} 
sempre movediço da memória, permanentemente construída e reconstruída no presente. Por isso mesmo Freud, em seu texto clássico sobre as lembranças de infâncias [3], vai dizer que elas são muito próximas da "invenção poética", o que nos auxilia a pensar que falar em memória, como em cultura, é fazer referência à invenção, nos obrigando a sair, analiticamente falando, da chave de conteúdos ou traços, mais ou menos fixados, sedimentados em algum tempo ou lugar, passíveis de serem pervertidos pelas transformações********. A cultura e a memória, aliás, só se mantêm, porque se modificam, de maneira que mais prudente é pensarmos em movimentos da memória, ritmados pelo jogo entre permanências e mudanças.

Tais ponderações indicam, ainda, os perigos envolvidos em tomarmos memória e história como noções sinônimas, ainda que elas apareçam frequentemente associadas. A distância talvez mais evidente entre elas tem a ver com o modo como lidam com o tempo: enquanto a história (ocidental) tira a sua razão de ser da cronologia (tempo das sucessões), a(s) memória(s) dela se afasta, interpelando outras formas de temporalidade (as simultaneidades).

Memória encadeia passado, presente e futuro, ninguém ousa duvidar. Assim que parece fundamental refletir sobre como os materiais e fontes coligidos pelos projetos repercutem no tempo presente e orientam ações, práticas e produções futuras. Tal abertura para o futuro poderia estar contemplada de modo mais enfático nos resultados esperados. O que não quer dizer que essa dimensão não apareça - como mencionei antes, mas estou aqui destacando ênfases. Por exemplo, ela se faz notar em um projeto sobre memórias de infância de funcionários da creche da USP, em que as lembranças sobre brincadeiras dos tempos de criança promoveram alterações, enriquecendo os currículos da creche e da Escola de Aplicação. Ou em outro, em que o acervo coligido de projetos de Iniciação Científica e graduação visa animar novos projetos, inclusive novas idas a campo orientadas pelas pesquisas levantadas. Ou ainda em um terceiro, que toma a memória da produção discente como base para promover uma reflexão mais ampla sobre o ensino de graduação.

Selecionei apenas três exemplos, que procuraram destacar a potência da memória como elemento propulsor de novas práticas e produções, pois tal elemento me parece muito importante para a reflexão sobre a memória em geral e a da Universidade em particular. Evidentemente os livros, filmes e acervos digitais (que correspondem aos resultados esperados em quase todos os projetos) são produções fundamentais, que devem ser previstas. Mas a pergunta que deixo para encerrar estas notas, nada conclusivas, é se não seria possível refletir sobre outras formas de aproveitamento desses materiais de modo a salientar suas possíveis repercussões sobre práticas e produções em curso.

Isto porque, se no plano dos levantamentos, as propostas são sensíveis à pluralidade de experiências, produções e práticas, as fontes de pesquisa se abrindo em várias direções, no plano dos resultados esperados, voltamos aos produtos de certo modo

$\star \star \star \star \star \star \star \star \star$ A invenção da cultura é precisamente o título do livro de Roy Wagner e ponto central de sua reflexão. 
“convencionais", sobretudo às publicações e produções audiovisuais. Não seria possível, aí também, abrir o leque e imaginar novas possibilidades, inventando outros produtos e abrindo horizontes inesperados?

\section{REFERÊNCIAS}

[1] CUNHA, M. C. da. Antropologia do Brasil: mito, história, etnicidade. São Paulo: Editora Brasiliense, 1986.

[2] CUNHA, M. C. da. Cultura com aspas e outros ensaios de antropologia. São Paulo: Cosac Naify, 2013.

[3] FREUD, S. Lembranças encobridoras. In: Edição Standard Brasileira das Obras Psicológicas completas de S. Freud. Tradução Jayme Salomão. vol. 3. Rio de Janeiro: Imago, 1980, p. 333-358. (Texto original publicado em 1899).

[4] GONÇALVES, J. A Retórica da perda: os discursos do patrimônio cultural no Brasil. Rio de Janeiro: Editora UFRJ/ IPHAN, 1996.

[5] RILES, A (ed). Documents. Artifacts of modern knowledge. Ann Arbor: University of Michigan Press, 2006.

[6] WAGNER, R. A invenção da cultura. Tradução Alexandre Morales e Marcela Coelho de Souza. São Paulo: Cosac Naify, 2010 (edição original de 1975).

FERNAN DA ARÊAS PEIXOTO professora adjunta da Faculdade de Filosofia, Letras e Ciências Humanas da Universidade de São Paulo (FFLCH-USP) e coordenadora do programa de pós-graduação em Antropologia Social da FFLCH-USP - e-mail: fpeixoto@uol.com.br 